\title{
Os think tanks brasileiros e suas contribuições para o pensamento social e político: um resgate histórico-exploratório sobre o Centro Brasileiro de Análise e Planejamento (Cebrap)
}

\author{
Juliana Cristina Rosa Hauck ${ }^{*}$ \\ Rafael Oliveira de Ávila**
}

\begin{abstract}
Resumo
Delinear a trajetória do pensamento político e social brasileiro não pode se furtar a um olhar sobre os think tanks (TTs). Ainda que sua definição seja incipiente e polêmica, é possível identificar situações sobre as quais não recai dúvida. Caso emblemático nesse contexto é o Cebrap - Centro Brasileiro de Análise e Planejamento. Entendido como um típico TT - organização dedicada à pesquisa e disseminação de ideias afetas às políticas públicas - o Cebrap albergou grandes intelectuais do país, servindo de ambiente de debates acerca dos principais problemas nacionais. Assim, se tornou referência nas ciências sociais, políticas, filosofia e na crítica literária e artística. Fernando Henrique Cardoso, José Giannotti, Paul Singer, Elza Berquó, Juarez Brandão, Francisco de Oliveira, José Serra, Cândido Procópio, Ruth Cardoso, Vilmar Faria, Bolívar Lamounier; estão entre seus principais intelectuais. O Cebrap também inspirou a criação de institutos similares e essa proeminência justifica sua centralidade no cenário intelectual brasileiro das últimas décadas. Para explorar esse destaque, o artigo faz uma elucidação teórica dos TTs e o Cebrap enquanto tal; segue-se um resgate histórico-político do centro e o impacto de suas produções intelectuais; e, por fim, uma análise de seu posicionamento enquanto um think tank à luz das teorias do tema.
\end{abstract}

Palavras-chave: Think tanks; Cebrap; Pensamento político e social brasileiro.

O delineamento da trajetória do pensamento político e social brasileiro pode ser significativamente enriquecido ao lançarmos um olhar para as organizações classificadas como think tanks. Ainda que possamos defini-las genericamente como organizações dedicadas principalmente à pesquisa de questões afetas às políticas públicas visando influenciá-las, por meio da disseminação de seus resultados de pesquisa, a identificação dos parâmetros para enquadramento de think tanks é incipiente e controversa tanto no mundo quanto no Brasil. É possível, no entanto, identificar com segurança alguns casos sobre os quais não recai dúvida sobre esse enquadramento. Um

\footnotetext{
* Mestranda em Ciência Política pela Universidade Federal de Minas Gerais.

** Doutor em Ciência da Informação pela Universidade Federal de Minas Gerais. Professor do Centro Universitário de Belo Horizonte (UniBH).
} 
dos exemplos mais emblemáticos no contexto brasileiro é o caso do Centro Brasileiro de Análise e Planejamento (Cebrap).

De acordo com os estudos de McGann (2013) o Brasil contava, em 2013, com 81 think tanks. Já Teixeira afirmou, em um artigo de 2012, que chega pelo menos a 100 TTs. Essas controvérsias de enquadramentos demonstram de partida, a fragilidade do conceito de think tank, porém, de qualquer forma, a proliferação dessas organizações no Brasil é indiscutível. O enfoque acadêmico sobre o fenômeno no país, no entanto, não é proporcional a essa proliferação, justificando a necessidade de estudos que revelem como se dá sua atuação no contexto mundial e, mais ainda, no contexto brasileiro. É nesse cenário que o enquadramento do Cebrap, enquanto TT, se faz produtivo como mais um aporte aos estudos sobre o fenômeno brasileiro e suas contribuições para auxiliar a invenção política e social do Brasil.

Ao longo de seus 40 anos, como será mostrado, o Cebrap albergou alguns dos maiores intelectuais do país, servindo de ambiente de debates acerca dos principais problemas nacionais e as possíveis alternativas para contorná-los. Como resultado desses esforços, se tornou referência da produção científica de vanguarda nas ciências sociais, filosofia e da crítica literária e artística. Durante a ditadura militar (1964-85), os trabalhos científicos desenvolvidos pelo Centro se mostraram destacadamente críticos e, em grande medida, independentes e resistentes ao regime. A transição para a redemocratização o consolidou como um centro de pesquisa independente e comprometido com a produção de conhecimento de alto nível contributivo para o pensamento brasileiro. Ainda assim, arrisca-se a dizer que o Cebrap se destacou, mais notadamente, no período ditatorial, enquanto resistência intelectual e centro de referência para a formação do pensamento político e social brasileiro. Hoje, o Centro divide esse espaço com diversas outras instituições similares que, graças à redemocratização, se proliferaram e se profissionalizaram significativamente, tais como as que nele se inspiraram, por exemplo.

O Cebrap não só abrigou e se constituiu em âmbito para a "gestação" intelectual de grandes pensadores brasileiros, como, a partir da sua experiência, outros institutos similares se formaram, como desdobramento direto desse órgão ou, no mínimo, tendo-o como exemplo. É o caso do Centro de Estudos de Cultura Contemporânea (Cedec), Instituto de Estudos Econômicos Sociais e Políticos de São Paulo (Idesp), Núcleo de Estudos das Populações (Nepo), o Instituto FHC (IFHC) e alguns centros de pesquisa sul-americanos. Dessa forma, nas palavras de Sorj, o Cebrap vem se apresentar como: 
Um caso privilegiado da rica e complexa relação entre a produção científica e a vida social e política, seja por suas origens, por seu papel central nas ciências sociais durante o regime autoritário, pelos problemas que atravessou com o processo de democratização ou pelo próprio fascínio que seus principais intelectuais exerceram sobre uma geração de jovens cientistas sociais nos anos 70. Neste sentido, respeitadas suas especificidades, o Cebrap pode ser visto como um exemplo e uma metáfora das complexas relações entre intelectuais e política, entre saber e poder, entre conhecimento e democracia na sociedade brasileira. (SORJ, 2001, p. 11).

Frente à proeminência e relevância no desenho do pensamento social e político brasileiro, que ficará clara ao longo deste artigo, é que se justifica a centralidade do Cebrap para o estudo que aqui se propõe como um dos think tanks mais relevantes para a formação do cenário intelectual político e social brasileiro das últimas décadas. Para apresentar essa relevância e seu posicionamento enquanto think tank, esta investigação está organizada em três seções. Na primeira, introduziu-se o tema de forma mais geral e sob o ponto de vista brasileiro, em particular, visando situar o Centro num contexto mais amplo. Em seguida, houve um resgate da trajetória histórico-política, dos intelectuais e dos principais impactos de suas produções e disseminação de suas ideias, visando explorar as contribuições mais marcantes da organização. Por fim, foram feitas considerações sobre seu posicionamento enquanto think tank brasileiro com o propósito contribuir para a compreensão de sua caracterização enquanto tal e ilustrar a relevância de estudos que analisem essas organizações sobre esse prisma, compreendendo melhor os atores não governamentais que orbitam a dinâmica política.

\section{Os Think tanks no mundo e no Brasil}

O termo think tank, utilizado para determinar o objeto que aqui se pretende explorar, tem sua origem nos países de língua inglesa. Devido à incipiência de uso do mesmo e da difusão do fenômeno no Brasil, ainda não há termo substitutivo em português. Ainda assim, alguns dos principais TTs brasileiros já se auto intitulam think tanks (para exemplos, ver websites: Fundação Getúlio Vargas ${ }^{1}$, Fundação $\mathrm{FHC}^{2}$, Instituto Millenium ${ }^{3}, \mathrm{CEBRAP}^{4}, \mathrm{CEBRI}^{5}$, dentre outros). Por isso, em concordância

\footnotetext{
${ }^{1}$ http://portal.fgv.br/think-tank-0.

${ }^{2}$ http://www.ifhc.org.br/publicacoes/think-tanks/.

${ }^{3}$ http://www.imil.org.br/blog/instituto-millenium-um-dos-melhores-tanks-das-amricas-sul-central/.

${ }^{4}$ http://www.cebrap.org.br/v2/news/view/425.

${ }^{5}$ http://cebri.org/portal/noticias/cebri-e-destacado-como-think-tank-mais-inovador-do-brasil.
} 
com estes e com a bibliografia mundial sobre o assunto, utilizaremos tal termo que foi introduzido, de acordo com McGann e Weaver (2002), durante a II Guerra Mundial, para caracterizar o ambiente seguro (tank) no qual os experts militares e civis se situavam para que pudessem desenvolver (think) planos de invasão e outras estratégias militares. Após a guerra, o uso do termo expandiu, em 1960, para descrever outros grupos de especialistas, preocupados com o estudo das relações internacionais e das questões estratégicas. Por volta de 1970, o termo think tanks foi aplicado amplamente a instituições focadas também em questões políticas, econômicas e sociais cotidianas (MCGANN; WEAVER, 2002).

Ainda que a terminologia tenha tido seu uso ampliado após 1960, segundo Rich (2004), a origem dos primeiros TTs remonta do começo do século XX. O autor mapeia as primeiras organizações com essas funções nos EUA, explicitando sua utilidade em um contexto em que os reformistas norte-americanos viam os especialistas como a saída para desenvolver soluções reais para as instabilidades sociais e políticas advindas da Revolução Industrial. McGann e Weaver (2002) entendem que essas organizações apareceram concomitantemente nos EUA e na Europa, na virada do século XX. Anteriormente encontrados quase que exclusivamente em democracias industriais avançadas ocidentais, os TTs vivenciaram um considerável crescimento desde os anos 1970 e grande proliferação, após a virada do século XXI.

Para Stone e Denham (2004), os TTs se proliferaram extensivamente na América Central e Latina, Ásia Leste e, mais recentemente, no Oriente Médio, Norte da África e África Subsaariana, especialmente após os períodos de (re) democratização com a descolonização africana, a derrocada de regimes ditatoriais latino-americanos e desintegração do bloco comunista.

Uma ampliação significativa de estudos sobre os TTs se deu, principalmente, após as décadas de 1990 e 2000, especialmente nos EUA e, em menor medida, em outros países anglo-saxões, respondendo, por um lado, a essa proliferação numérica e a relevância dos TTs no horizonte social e político desses países. Alguns estudiosos têm destacado, por outro lado, a atuação mais recente desses atores como muito similar à de grupos de interesse e organizações de advocacy, conforme ressaltado por Silverstein 
$(2013)^{6}$, Crawford $(2013)^{7}$ e Moncada $(2013)^{8}$. Essas fronteiras nebulosas com outras organizações interessadas no processo político vêm se tornando, progressivamente, um dos pontos principais que pautam o debate dos estudos dos think tanks, uma vez apontados entraves para a mobilização de uma definição compreensiva de TT, especialmente em uma perspectiva comparada (MCGANN; JOHNSON, 2005; STONE, 2007; MEDVETZ, 2008; RICH, 2004). Esse é o motivo pelo qual, introdutoriamente, já se colocou a possibilidade ou o fácil enquadramento do Cebrap enquanto TT, na definição mais tradicional. Vale destacar, no entanto, que, como coloca Medvetz (2008, p. 2) “[...] o dilema da definição ainda não está resolvido."

O Cebrap se enquadra nas definições mais seminais de TTs, apresentadas por autores como Weaver (1989 apud MCGANN e WEAVER, 2002, p. 4): “[...] organizações de pesquisa, não governamentais, sem fins lucrativos, com substantiva autonomia organizacional do governo e de interesses societais como de empresas, grupos de interesses e partidos políticos.” Ou como Rich (2004, p. 11): “[...] organizações independentes, não baseadas em interesses, sem fins lucrativos, que produzem e principalmente se apoiam na expertise e nas ideias para obter apoio e influência no processo de elaboração de políticas."

Os dois conceitos, muito referenciados no campo de estudo, utilizam como eixo principal a autonomia/ independência da organização de interesses e afiliações. A maioria dos autores, porém, reconhece, em algum momento, que tratar de autonomia em organizações que dependem de recursos de terceiros para sua sobrevivência deverá ser sempre algo a ser analisado de forma relativa. E como argumentam Stone e Denham (2004), falar de independência como uma característica definidora de think tanks faz pouco sentido em alguns contextos culturais, especialmente em países em desenvolvimento e países transicionais .

Weaver e McGann (2002) afirmam que, quando os think tanks se expandiram geograficamente, tiveram que se adaptar a novas condições impostas pelos contextos nacionais. Nas diversas regiões, os think tanks encararam diferentes conjuntos de

\footnotetext{
${ }^{6}$ Ver: Ken Silverstein (2013), "The Great Think-Tank Bubble”, disponível em: http://www.newrep ublic.com/article/112381/salary-inflation-beltway-think-tanks.

7 Ver: Alan Crawford (2013), “Think tanks: A New Brand of Lobbying Firms?”, disponível em: http://pac.org/news/think-tanks-a-new-brand-of-lobbying-firms.

8 Ver: Andrea Moncada (2013), “Are think tanks the new lobbyists?”, disponível em: http://onthinktanks.org/2013/03/08/are-think-tanks-the-new-lobbyists.

${ }^{9}$ Ver também Stone (2007), Medvetz (2008, 2010) e Pautz (2011).
} 
desafios que os forçaram a desenvolver modos inovadores de se manter. A ausência de tradições filantrópicas fortes ou legislações tributárias que encorajem a filantropia privada levou os TTs, em muitos desses países, a serem primariamente fundados por governos, partidos políticos, ou doadores internacionais, como é o caso de alguns países asiáticos, Rússia e Comunidade Estados Independentes, assim como o próprio Brasil. Estando presentes em diversificados países, e, portanto, operando em uma grande variedade de sistemas políticos, se engajam em uma amplitude de atividades relacionadas às políticas e compreendem um conjunto diverso de instituições que tem variados formatos - geralmente diferenciando-se em função de suas afiliações organizacionais mais fortes. ${ }^{10}$

Cada vez apresentando mais sobreposições de funções e formatos com unidades governamentais de pesquisa e aconselhamento de políticas, institutos de pesquisa de universidades, grupos de interesses e organizações de advocacy e, muitas vezes, formalizando afiliações diretas com essas organizações, os TTs têm constituído áreas cinzentas nas fronteiras de diferenciação com elas. O Cebrap, no entanto, não representa os formatos mais polêmicos de think tanks, acima destacados. Porém, é nesse norte conceitual nebuloso que o Brasil, em princípio, de forma geral, se enquadra.

O surgimento do fenômeno dos TTs no país, de início, faz coro a essas controvérsias conceituais mundiais. A trajetória de alguns dos primeiros TTs pode ser atribuída ao primeiro período do governo Vargas (1930-1934). Um estudo do $\mathrm{CPDOC} / \mathrm{FGV}$ demonstra as motivações e providências varguistas para conferir maior racionalidade às ações públicas:

\footnotetext{
Fiel ao princípio de que era necessário aplacar as disputas políticas para promover o desenvolvimento do país, também no plano administrativo, o governo do Estado Novo buscou eficiência e racionalidade [...] a preocupação com a formação de pessoal para atuar na administração daria origem à Fundação Getúlio Vargas (FGV). Foi o desejo de dispor de informações estatísticas confiáveis que levou à valorização do Instituto Brasileiro de Geografia e Estatística (IBGE). Na área econômica, criaram-se, durante o Estado Novo, inúmeros conselhos e órgãos técnicos cuja função era promover estudos e discussões, assessorar o governo na elaboração e na execução de suas decisões, e ainda propiciar o acesso de setores empresariais ao aparelho estatal. (CPDOC/FGV, 1997).
}

Ainda que não tivessem o intuito explícito de influenciar as políticas públicas de maneira desvinculada dos interesses governamentais, ao longo do tempo, o desenvolvimento de suas atividades de pesquisa e disseminação de ideias,

\footnotetext{
${ }^{10}$ Ver McGann e Weaver (2002).
} 
especialmente após a redemocratização, os alçou a tal condição. A Fundação Getúlio Vargas (FGV), fundada em 1944, por exemplo, é recorrentemente reconhecida como um dos think tank brasileiros mais relevantes segundo um ranking mundial de TTs que vem referenciando o campo de estudo sobre o assunto - o Global got-to think tanks Index. ${ }^{11}$ O Instituto Superior de Estudos Brasileiro (ISEB) foi outra organização criada nesses moldes, como órgão do Ministério da Educação, mas foi extinto com a instauração do regime militar, por sua forte vinculação (ideológica e financeira) ao governo Juscelino Kubitscheck.

A partir daí, diversas outras organizações com esse propósito de pensar criticamente a ação pública e influenciar a dinâmica política, foram surgindo. Fatores como a ausência de uma cultura filantrópica, de doações para financiamento de atividades de think tanks, têm sido apontados por alguns autores como determinantes para a trajetória de proliferação dos TTs no Brasil, fortemente atrelada à sua relação com a estrutura governamental (MCGANN; JOHNSON, 2005; CHACEL, 2005). Nas palavras de Chacel (2005, p. 569 - tradução nossa): “[...] para os TTs brasileiros, o aperto econômico impôs um pragmatismo que diminuiu sua liberdade de escolha em determinar suas agendas de pesquisa com foco no interesse público." Assim, essas organizações acabam por contaminar suas agendas de pesquisa devido aos constrangimentos gerados por suas afiliações com fontes de recursos, tanto com o setor privado, quanto com o setor governamental, mas principalmente com este último, maior demandante de informações afetas às políticas públicas.

Dessa forma, pensar um conceito de think tanks para o caso brasileiro, se aplicado em sua perspectiva mais ampla, inclui até mesmo algumas organizações que, em princípio, deveriam ser classificadas como típicos órgãos de assessoramento de governo, como o caso do IPEA (Instituto de Pesquisa Econômica Aplicada/Ministério do Planejamento Orçamento e Gestão). Segundo Costa, a fundação do IPEA marca uma das maiores contradições da ditadura militar brasileira, que, mesmo marcada pelo "ambiente de perseguição política e ideológica" promove a fundação e projeção do Instituto em 1964 como “[...] uma espécie de consciência crítica a apontar, inclusive, os erros e riscos do projeto econômico que os militares implantavam." (COSTA, 2011, p. 1).

\footnotetext{
${ }^{11}$ Disponível em: http://gotothinktank.com/rankings.
} 
Nos mesmos moldes do IPEA, outros TTs brasileiros surgiram sob a tutela governamental, como, por exemplo: Escola Superior de Guerra (Ministério da Defesa 1949), Fundação Joaquim Nabuco (Ministério da Educação) - 1949, Fundação Oswaldo Cruz (Ministério da Saúde) ${ }^{12}$, Fundação Alexandre Gusmão (Ministério das Relações Exteriores) - 1971. Surgem também, ao longo das décadas, os TTs vinculados a instituições universitárias ou provenientes destas como o Instituto de Medicina Social (UERJ) - 1969, Fundação Instituto de Pesquisas Econômicas (USP) - 1973, Coordenação Programas de pós-graduação em Engenharia (UFRJ) - 1963 e o próprio Cebrap, em 1969, como abrigo intelectual de estudiosos da USP; entre outros.

A partir dos últimos anos da ditadura militar, e especialmente após o início da década de 1980, a proliferação de think tanks com menor vinculação governamental no Brasil aumentou significativamente. Seja por estímulos financeiros internacionais, como das Fundações Ford e Rockefeller, de agências internacionais (Sistema ONU, Banco Interamericano de Desenvolvimento), seja por iniciativa de partidos políticos, grupos de interesse ou sindicatos que se reorganizavam com a restauração do sistema político democrático. Alguns exemplos são os Institutos Liberais, Instituto Fernand Braudel, Centro Brasileiro de Relações Internacionais, Instituto de Estudos do Comércio e Negociações Internacionais, Instituto Teotônio Vilela e diversos outros TTs. O Cebrap, objeto de interesse deste artigo, é um caso pioneiro nessa categoria de TT, com sua parceria junto a Fundação Ford, já em 1969. A seguir, apresentamos sua trajetória e contribuições para a história política e social brasileira.

\section{Trajetória Histórico-política do Cebrap e suas Contribuições Ideológicas ${ }^{13}$}

A história do Cebrap se inicia com o "Seminário do Capital", considerado sua estrutura inaugural, que consistia em um grupo formado por alguns dos seus principais fundadores para a leitura crítica e o debate aprofundado sobre a obra de Karl Marx (SORJ, 2001; MOURA; MONTERO, 2009). A importância desse seminário, no entendimento de Sorj, suplantou seu valor intelectual para funcionar como um "[...] elemento cristalizador da identidade de um grupo geracional" (SORJ, 2001, p.20).

\footnotetext{
${ }^{12}$ De fato, a história da FIOCRUZ começa em 1900, com a criação do Instituto Soroterápico Federal, no Rio de Janeiro. Disponível em: http://portal.fiocruz.br/pt-br/node/119.

${ }^{13}$ Utilizou-se como principal fonte de dados os estudos de Sorj (2001), Moura e Montero (2009) e o documentário "Retrato de Grupo" dirigido por Henri Arraes Gervaiseau (2009). Tratam-se, portanto, de fontes secundárias que registram a história do Centro.
} 
Ainda que o Seminário tenha se iniciado por volta de 1958, a criação formal do Centro só se dará em maio de 1969, propiciada pela pressão sentida pelos intelectuais em posicionar-se frente à ditadura e abrigar-se dos desdobramentos provocados pelo Ato Institucional $\mathrm{n}^{\mathrm{o}}$. 5, de 1968, que, entre as diversas medidas, aposentou compulsoriamente parte dos quadros docentes das universidades. A fundação do Cebrap, portanto, pode ser considerada uma manobra improvável, haja vista o contexto de acirramento do regime ditatorial. Mas, para que essa manobra fosse possível, dois fatos importantes contribuíram para a sobrevivência imediata do Centro: o financiamento da Fundação Ford e os vínculos estratégicos que a instituição conseguiu manter com setores mais liberais do empresariado, da classe política, da Igreja e da intelectualidade em geral (SORJ, 2001).

O núcleo inicial de pesquisadores era formado por Juarez Brandão Lopes, Fernando Henrique Cardoso, Paul Singer, Elza Berquó, Cândido Procópio, Ferreira Camargo, José Artur Giannotti e Octávio Ianni, este último a partir de 1970. Entre estes, havia outros pesquisadores não permanentes como é o caso de Francisco Weffort e Boris Fausto, Regis de C. Andrade, Luis Werneck Vianna, Fabio Munhoz e Maria Hermínia Tavares de Almeida, entre outros. Alguns acréscimos, ao longo dos anos, foram: Francisco de Oliveira e Bolívar Lamounier, em 1970, Vilmar Faria e Carlos Estevam Martins, em 1971, e Vinícius Caldeira Brandt, em 1974. A partir dessa data, na década de 70, o grupo não será ampliado, a não ser pela chegada de José Serra, líder estudantil exilado que trabalhava como economista no Chile; e, pelo contrário, sofrerá "baixa" a partir de 1976.

O período que se segue a 1971 é considerado de consolidação, especialmente levando em conta que nesse ano tem início as publicações do Cebrap. Essa fase, na análise de Sorj (2001), vai até 1978, marcado por dois contextos que o autor entende serem claramente definíveis, do ponto de vista societário. A primeira corresponde ao governo Médici, até 1974, marcado pela repressão política e o milagre econômico. A segunda fase (1974-79), correspondente ao governo Geisel, de revitalização das oposições aglutinadas no Movimento Democrático Brasileiro (MDB), de abertura política controlada, “[...] num contexto em que a economia começava a apresentar os primeiros sintomas que se transformarão no final da década em crise inflacionária e recessão." (SORJ, 2001, p. 41).

Na memória dos pesquisadores, o período de 1971 a 1975 permanece como o período heroico, de resistência e consolidação da vida interna do Centro, de grande 
dedicação ao trabalho de pesquisa e de centralidade existencial do Cebrap. De 1975 em diante, a instituição passa a ser uma espécie de plataforma a partir da qual se consolidaram outros empregos, aumentando a participação intelectual e política de seus membros, tornando mais frágeis seus vínculos com a instituição (MOURA; MONTERO, 2009). E claramente a partir de 1976, à medida que a problemática das mudanças estruturais e a expansão do capitalismo passam a ser insuficientes como marco orientador dos alinhamentos teóricos, o Cebrap perde sua problemática unificadora em torno da resistência à ditadura.

Por fim, a fase que Sorj (2001) considera de crise, redefinições e busca de uma nova identidade, vai de 1979 a 2001. A crise que começa a se instaurar de 1979 em diante, se deve, em grande medida, a alguns fatores, tais como: criação do novo sistema partidário que divide o Centro entre simpatizantes do PMDB e do PT; anistia e reintegração de pesquisadores do Cebrap às universidades que gera uma grande queda da dedicação de tempo de trabalho ao Centro; saída permanente de membros do staff $f^{4}$ e; desafio constante do financiamento.

Quanto à divisão partidária supracitada, as colocações de Paul Singer no documentário "Retrato de Grupo" parecem ilustrar adequadamente. Quando perguntado sobre haver um momento, no que se refere à vida partidária, que dividiu os pesquisadores "cebrapianos", Singer responde:

Sim. No início quem tinha atividade política foi para o PMDB. O Ulysses Guimarães foi ao Cebrap pedir ajuda para fazer um programa para o partido, por exemplo. Eu não cheguei a me filiar ao PMDB, mas outros como o Francisco Weffort, e o próprio Fernando Henrique, se filiaram. Mas a criação do PT foi um divisor de águas, porque boa parte da esquerda ficou no PMDB, nem todos foram para o PT. Essa divisão atingiu o Cebrap: o Chico de Oliveira, o Vinícius e eu fomos para o PT; o Fernando Henrique, o Serra, o Juarez Brandão e a Elza não, ficaram no PMDB. (GERVAISEAU, 2009).

No entendimento de Sorj (2001), o advento da democracia não só acabou com o consenso interno do Cebrap, como os novos temas emergentes colocavam questões para as quais a instituição não tinha uma contribuição singular a oferecer. Passado o período de luta contra a ditadura, e com a consolidação dos novos centros de pesquisa, o Cebrap perdeu seu lugar privilegiado (SORJ, 2001), ainda que, na atualidade, continue a se

\footnotetext{
${ }^{14}$ Quanto à saída de membros do staff, vale destacar as de: Octavio Ianni (entendendo que o Centro não mais cumpria sua missão de resistência); Fernando Henrique (que assume a vaga de Senador); José Serra (que assume a vaga de Secretário Estadual de Planejamento no governo de Franco Montoro em São Paulo); Francisco Weffort e Boris Fausto (que saem para compor o CEDEC); Carlos Estevam Martins e Vilmar Faria que participam da direção de um organismo público; Bolívar Lamounier (que funda o IDESP), dentre outros.
} 
apresentar como um think tank de destaque, se configurando como um dos 45 TTs mais bem avaliados na América Latina e Central - 14 ${ }^{\mathrm{a}}$ posição; o $5^{\circ}$ melhor TT brasileiro na área de políticas públicas; e está entre os 50 melhores do mundo na categoria Outstanding Policy-Oriented Research Programs, segundo McGann (2013).

Nas poucas obras que buscam retratar o papel do Cebrap que tivemos acesso, o fantasma do financiamento também fica marcado como um dos grandes dramas do Centro. O Cebrap sofreu, ao longo da década de 70, uma série de crises de financiamento, em particular em 1976 e em 1979-80, típicas na realidade dos think tanks como amplamente relatado pela literatura. $\mathrm{O}$ enorme capital intelectual e social dos seus fundadores, de acordo com os estudos de Sorj (2001), assegurou fontes de financiamento que viabilizaram a instituição, mas esses recursos vinham associados a uma agenda de pesquisa alheia às preocupações intelectuais da maioria dos membros do staff. Isso criou, segundo ele, certa esquizofrenia, em que os trabalhos de maior impacto intelectual foram escritos à margem dos trabalhos de pesquisa financiados. Essa dinâmica problemática também vai fragilizar o Centro de outras formas: do ponto de vista das tensões intelectuais; da absorção de pesquisadores juniores e sua filiação junto aos seniores; e, também, do ponto de vista da "desfiliação", ao longo dos anos, dos pesquisadores principais que se viam frente à necessidade de buscar outras fontes de renda, diminuindo sua dedicação ao Cebrap.

$\mathrm{Na}$ perspectiva operacional, a dinâmica característica de funcionamento do Cebrap, que consagraria seus feitos bem como o alçaria a modelo de TT no Brasil e na América do Sul era fortemente marcada pelas especificidades reveladoras da vanguarda da sua dinâmica de funcionamento: multi/interdisciplinaridade (propiciada pelas variadas origens intelectuais dos integrantes); pela busca da neutralidade ideológica dos estudos; pela inexistência de estruturas formais de tomada de decisões; e, por um ambiente propício ao debate, proporcionado pelos "mesões" (encontros em torno de um tema apresentado por parte dos estudiosos, seguido de debates) (MOURA; MONTERO, 2009; SORJ, 2001). Essa dinâmica, no entanto, não significou inexistência de conflitos ou tensões. No entendimento de Sorj, a agenda comum era responsável pela continuidade e coesão do Cebrap: “[...] alvo de crítica: a ditadura; um objetivo: a democracia, e aumentou sua coesão interna pelo isolamento da vida universitária devido à repressão política.” (SORJ, 2001, p. 66). 


\section{Obras e pensamento político e social de vanguarda}

No que se refere às obras de maior projeção como contribuições intelectuais, destacam-se: FHC com seu estudo sobre Dependência e Desenvolvimento da América Latina (1970), que alcançou projeção internacional; O modelo político brasileiro e outros ensaios (1972), também de Fernando Henrique Cardoso; os estudos de José Serra e Maria da Conceição Tavares sobre Economia Brasileira (1971); os de Francisco de Oliveira com Crítica da razão dualista (1972); e Paul Singer, As contradições do milagre (1973); sem sombra de dúvida têm forte impacto no processo de formação do pensamento social e político brasileiro. Segundo Fernando Henrique, ele próprio e Bolívar Lamounier engrossam essas contribuições desenvolvendo um estudo, em 1974 que “[...] mudava o rumo das discussões de 'classe e o partido' para 'a eleição e os partidos' abrindo espaço para esse tipo de discussão-temática já à espreita da abertura política." (MOURA; MONTERO, 2009, p. 36). Destacam-se ainda, São Paulo 1975: crescimento e pobreza, de (1976), escrito por José Álvaro Moisés, Lúcio Kowarick, Maria Hermínia Tavares de Almeida, Paul Israel Singer e Vinícius Caldeira Brant; O povo em movimento (1982), coordenado por Paul Singer e Vinícius Caldeira Brant; e São Paulo: trabalhar e viver, de (1989), coordenado por Vinícius Caldeira Brant. Esses são outros exemplos de publicações que fizeram história no pensamento social e político brasileiro.

De acordo com Elza Berquó (MOURA; MONTERO, 2009, p. 100) o Cebrap contribuiu para a mudança de agenda do campo dos estudos de população, haja vista seu papel junto à Comissão de População e Desenvolvimento da CLACSO, em princípios de 1971, e que representava uma transformação da comissão de Estudos Demográficos. O trabalho de Berquó, frente ao Cebrap em princípio e até os dias atuais, liderando o Núcleo de Estudos de População (Nepo) reitera seu protagonismo (e, dessa forma, o protagonismo do Cebrap) na vanguarda do estudos demográficos brasileiros no que se refere á demografia da população negra, esterilizações femininas, contraposição às políticas de controle populacional, saúde e direitos reprodutivos nas conferências de populações da ONU, são alguns dos temas que a pesquisadora conduziu e que impactaram as políticas públicas referentes ao assunto, ao longo das últimas décadas (MOURA; MONTERO, 2009).

Ao analisar a trajetória de contribuições intelectuais do Cebrap, Chico de Oliveira destaca que é marcada por três principais fases: 
A primeira, nos anos 1970, é a grande fase, no meu juízo. Todos os grandes temas da sociologia latino-americana e do debate brasileiro se cruzaram aqui. Aqui se produziu discussão sobre marginalidade, que era quente na América Latina. Aqui se produzir a discussão sobre o declínio da fecundidade, porque o fantasma malthusiano estava aí, mas o Cebrap enfrentou. Aqui se produziu, de forma bastante discreta, uma interpretação da teologia da libertação [...] Aqui se produziu a discussão que o Fernando Henrique que conduzia sobre os limites da democracia, do autoritarismo e sobre a economia brasileira, que era um tema que trabalhávamos eu e o Paul Singer. Aqui se produziram discussões sobre a nova fase da agricultura brasileira. (MOURA; MONTEIRO, 2009, p. 172).

O segundo período, na concepção de Chico, é de 1980 a 1990. Segundo o autor, um período de muita ajuda à universidade e aproximação com a política institucional, marcado pela saída de Fernando Henrique Cardoso do Centro. A partir de 1990, Chico entende que a política partidária "entrou e dividiu"; que o Cebrap conseguiu sair dessa crise profissionalizando-se e continua sendo um centro de pesquisas importante (ver Seção 3), ainda que hoje não tenha a mesma relevância do passado porque concorre com outras instituições e com a universidade, que cresceram e melhoraram muito.

De maneira geral, FHC sumariza como principais contribuições do Cebrap a eliminação da compartimentalização das ciências sociais, "juntando demografia, filosofia economia, as diversas áreas do pensamento e da análise social". Ele ainda destaca a certeza de que o Centro deu suas contribuições para reformular a visão da esquerda

[...] a respeito do jogo político, do jogo democrático. Contribuímos com uma visão mais anuançada da política, uma visão institucional, que praticamente não existia em nosso meio. Eu também diria que participamos da construção da temática dos movimentos sociais e da questão das minorias como temas de relevância política. (MOURA; MONTERO, 2009, p. 39).

\section{(Re)conformação do sistema político brasileiro - os partidos pós-ditadura}

A influência indireta e direta dos intelectuais do Cebrap da ditadura na formação dos novos partidos que irão (re)compor o sistema político brasileiro a partir da abertura é notória. De acordo com Lúcio Kowarick, “[...] os intelectuais foram vitais na formação dos principais partidos políticos da atualidade, o PT e o PSDB. Tiveram também um papel de destaque na luta contra a ditadura: o Cebrap é um exemplo disso e, de uma forma ou de outra, nossas falas e nossos escritos tiveram um papel relevante." (MOURA; MONTERO, 2009, p. 139). A colaboração entre membros do Cebrap e o MDB começa em 1974, desde os auxílios ao partido na CPI das multinacionais, a 
assessoria na concepção de seu programa partidário e aumenta nos anos seguintes, particularmente a partir de 1978, com a integração de Fernando Henrique Cardoso à vida do partido.

Segundo José Serra , em 1979, os "cebrapianos" haviam chegado a trabalhar na ideia de um partido popular "junto com o Lula e os sindicalistas de São Bernardo". Juntamente com Fernando Henrique, Plínio Sampaio, Almino Affonso, José Serra afirma terem feito “[...] até uma reunião em São Bernardo, em 1979, mas quem pontificou na reunião foi um trotskista, o Paulo Ostromov, que era, se eu não me engano, do Sindicato dos Chapeleiros, que, curiosamente, teve a cobertura do Lula." (MOURA; MONTERO, 2009, p. 189). As contribuições para a gestação e concepção dos principais partidos brasileiros da atualidade (PSDB, PMDB e PT) por parte dos membros do Centro, portanto, não deixam dúvidas.

\section{O Cebrap enquanto Think tank}

Nas primeiras seções, foi caracterizada a inquestionável contribuição do Cebrap para a trajetória social e política brasileira. Essas contribuições se deram não somente do ponto de vista da reflexão teórica, mas da prática política, configurando o centro como um âmbito emanador de ideias afetas às políticas públicas no país. Após identifica-lo historicamente em sua ação como um think tank, é profícuo fazê-lo, objetivamente, também a partir da mobilização da literatura especializada sobre o tema. E, para tal, é útil a análise de sua atuação, na busca de influenciar o fluxo de ideias sob os termos teóricos que vêm sendo produzidos para caracterização dos think tanks no campo de estudo dessas organizações.

Conceitualmente, como supra-argumentado, em essência, a definição de think tanks se restringe, em sua perspectiva mais simplista, às organizações que realizam/editam pesquisas sobre assuntos afetos às políticas públicas e disseminam os resultados obtidos visando influenciar a conformação da opinião pública e, principalmente, dos tomadores de decisões políticas, impactando o processo político. Um dos caminhos para a identificação concreta de indicadores que enquadrem uma organização nestes termos é o caminho da visibilidade. Isto é, identificar as estratégias e os esforços realizados pela organização para buscar promover suas ideias e, assim, obter influência junto à opinião pública e tomadores de decisão. Abelson (2009), um dos estudiosos dedicados aos TTs mais destacados mundialmente, desenvolveu estudos para 
a definição de tipos de indicadores para identificar como os TTs "disseminam suas ideias" para que sejam "compradas" no "mercado de ideias". Esses indicadores, para o autor, revelariam a utilização, por parte dos TTs, de estratégias de "marketing de ideias" (ABELSON, 2009, p. 77). Ou seja, as formas de disseminação de ideias - objetivo típico dos think tanks - estão, para o autor, divididas em dois tipos: as estratégias privadas, que dizem respeito às abordagens diretas, realizadas privadamente, aos policy makers; e as públicas, que dizem respeito às abordagens mais amplas, direcionadas ao público geral através da mídia, ou a públicos focalizados, mas não individuais, por meio de eventos, publicações e outras estratégias.

Como conformadores de estratégia privada Abelson elenca os seguintes indicadores: integração em quadros do governo (em gabinetes, sub-gabinetes e cargos burocráticos nas administrações); servir em forças-tarefa de políticas e times de transição durante eleições presidenciais e em comitês de aconselhamento presidencial; manter escritórios de liasion com os âmbitos de elaboração de políticas; convites a policymakers selecionados para participar em conferências, seminários e workshops; permissão a burocratas para trabalharem nos TTs em um período de tempo limitado; oferecer a ex-policymakers posições nos TTs; preparar estudos e briefs de políticas para policymakers. Como indicadores para condução de estratégia pública, o autor elenca os seguintes indicadores: promover fóruns públicos e conferências para discutir várias questões políticas, domésticas e externas; encorajar estudiosos a dar palestras públicas e consultorias; depor perante comitês e subcomitês do congresso e parlamento; publicar em livros, revistas de opinião, newsletters, resenhas (briefs) sobre políticas e jornais de ampla distribuição; criar mailings para facilitar a transmissão de novas publicações e postar informações-chave sobre os estudos de seu instituto nos sites de internet; abordar o público durante campanhas anuais de fundraising; aumentar sua exposição na mídia (ABELSON, 2009). Acrescentaríamos ainda um indicador presente em outras literaturas que permitem conceber um conjunto completo de indicadores que reflitam as estratégias de promoção de ideias por think tanks: capacidade de conceder titulações de graduações acadêmicas (MEDVETZ, 2010; RICH, 2004).

Desses indicadores elencados por Abelson, alguns se destacam como mais comuns ao comportamento de think tanks (ABELSON, 2009; RICH, 2004; MEDVETZ, 2010) e foram utilizados para o levantamento de dados qualitativos referentes à atuação do Cebrap e suas estratégias enquanto think tank. A saber: integração em quadros do governo; servir em forças-tarefa de políticas e times de transição durante eleições 
presidenciais e em comitês de aconselhamento presidencial; convites a policymakers selecionados para participar em conferências, seminários e workshops; preparar estudos e briefs de políticas para formuladores de políticas; promover fóruns públicos e conferências para discutir várias questões políticas, domésticas e externas; encorajar estudiosos a dar palestras públicas e consultorias; depor perante comitês e subcomitês do congresso e parlamento; publicar em livros, revistas de opinião, newsletters, resenhas (briefs) sobre políticas e jornais de ampla distribuição; criar mailings para facilitar a transmissão de novas publicações e postar informações-chave sobre os estudos de seu instituto nos sites de internet; aumentar sua exposição na mídia. A seguir, apresentamos os dados analisados qualitativamente com o propósito de compreender um pouco mais sobre o perfil estratégico de disseminação de ideias do Cebrap.

\section{Integração nos quadros de governo - estratégia privada}

A integração nos quadros de governo, segundo Abelson (2009), é uma estratégia de marketing de ideias de tipo privada, que visa interferir diretamente no processo decisório a partir de uma posição de decisão (gabinetes ou sub-gabinetes) ou no assessoramento à decisão, sugerindo direções na ação política. De fato, acredita-se que não havia no Cebrap, até tempos mais recentes, uma política deliberada entre seus intelectuais para a integração em quadros de governo. Ainda assim, à medida que as oportunidades desse tipo iam surgindo, diversas delas foram aproveitadas. Paul Singer reitera essa posição de que não houve diretriz deliberada de ocupação de cargos públicos. Mas, segundo o autor, depois da redemocratização, esse almejo por parte dos pesquisadores, de integrar-se ao governo, fica mais explícito:

Realmente não pensávamos que fossemos integrar governos, e acho que ninguém estava muito preocupado com isso. Quando nós fundamos o Cebrap, a situação era tão ruim que essa perspectiva estava muito longe de nossos horizontes, naquela época. Mas depois, com a redemocratização, sim. Nesse momento abre-se todo um processo de participação política ativa. $\mathrm{Na}$ formação do PMDB, do PT, houve uma ativa participação de todos nós do Cebrap, até em situação de liderança, o que tornou normal, mais tarde, ocupar cargos na administração pública. O primeiro foi realmente o Fernando Henrique, ao aceitar ser candidato a senador em 1978 e ser eleito suplente do André Franco Montoro, o que o levou ao Senado depois e o Montoro ter sido eleito governador no estado de São Paulo. E então, junto com os governadores de oposição eleitos em 1982, começamos a ir para o governo acho que o Serra foi um dos primeiros, efetivamente. (MOURA; MONTERO, 2009, p. 86). 
Giannotti acreditava que o papel do intelectual não é o de ocupar cargos públicos. Por isso afirmou, em entrevista para o livro de celebração dos 40 anos do Cebrap, que a ocupação de cargos públicos por diversos intelectuais do Cebrap não se deu de forma programada: "as coisas foram caminhando pra isso". No entanto, no caso do Cebrap, essa integração claramente não significou a integração nos quadros governo nos termos de Abelson, com objetivos de exercer influência no processo político em concordância com "achados" de pesquisa (MOURA; MONTERO, 2009, p. 66). Muitos dos intelectuais que foram para o governo, muitas vezes, tomaram posições políticas até mesmo surpreendentes frente a sua trajetória de pesquisa, como foi, destacadamente, o caso de Fernando Henrique Cardoso. E, de forma geral, as motivações para essas integrações parecem estar muito mais ligadas a interesses de carreira e de complementação salarial do que a promoção de ideias condensadas internamente ao Cebrap, na maioria dos casos. A atuação atual do Instituto, nesse sentido, não foi identificada como uma diretriz deliberada de atuação.

\section{Servir em força-tarefa de políticas e times de transição - estratégia privada}

Amplamente documentada, a participação dos intelectuais na composição de programas partidários foi citada aqui nas seções anteriores. Adicionalmente a isso, a participação dos intelectuais na concepção de políticas, em regime de força-tarefa pode ser fortemente exemplificada pelo caso de Vilmar Faria, na Assessoria Especial da Presidência de Fernando Henrique, assim como Francisco Weffort, no PT, e Elza Berquó, em seus assessoramentos para as delegações brasileiras junto a Conferências da ONU, para discutir as políticas de Saúde e Direitos Reprodutivos. Caracterizam-se, dessa forma, como esforços deliberados para intervenção no processo político sempre que surgiam as oportunidades, em situações críticas.

\section{Publicações em mídia especializada e/ou ampla mídia - estratégia pública}

O caminho da publicação das ideias é uma decisão deliberada tomada a partir de 1971, quando o Cebrap decide divulgar seu trabalho através de publicações, tanto para ter um maior impacto como para diminuir as suspeitas do aparelho repressivo sobre o tipo de atividade da instituição. Foram duas as publicações do Centro: Estudos Cebrap e Cadernos Cebrap, além da publicação eventual de livros. A primeira, uma revista periódica, tinha como objetivo atingir um público mais amplo e a segunda, num formato 
mais simples, com divulgação mais restrita, apresentava trabalhos de porte médio e que posteriormente eram muitas vezes transformados em artigos ou livros. Segundo Francisco de Oliveira, a história da principal publicação do Cebrap vem de uma longa trajetória:

\begin{abstract}
A Novos Estudos Cebrap veio da antiga Estudos, e hoje está entre as melhores revistas acadêmicas do Brasil. Passou por uma fase que eu a dirigi, que foi uma tentativa de torná-la mais atuante, intervir mais rapidamente na conjuntura, então a gente deu o nome de Novos Estudos Cebrap. Começou em 1980, e depois eu me afastei [...] Em 1980 e poucos, Giannotti convidou o Rodrigo Naves [...] naquele breve período, o foco era esse: vamos intervir, vamos levar essas posições pra fora. (MOURA; MONTERO, 2009, p.171 - grifos nossos).
\end{abstract}

A presença do Cebrap junto ao grande público também se deu através de artigos escritos, particularmente, por Fernando Henrique Cardoso e Paul Singer para o semanário Opinião, dirigido por Fernando Gasparian e, durante vários anos, principal fórum de ideias e debates das tendências oposicionistas. Posteriormente, com o surgimento do semanário Movimento, os membros do Cebrap colaboraram em ambos os periódicos (SORJ, 2001). Além dos casos acima citados, de publicações sistemáticas e frequentes, há de se destacar os livros e estudos que tomavam ampla proporção junto ao público especializado.

Segundo o próprio Cebrap, ao longo de suas quatro décadas, o Centro editou 27 livros, alguns decisivos na história intelectual brasileira como já mencionado. ${ }^{15} \mathrm{E}$ sempre manteve publicações seriadas: a Estudos Cebrap (27 números, entre 1971 e 1980), e os Cadernos Cebrap - Nova Série (38 números, entre 1971 e 1986), os Cadernos de Pesquisa (8 números) e os Estudos de População Cebrap (8 números, entre 1977 e 1982). Desde 1981, circula a Novos Estudos Cebrap, publicação trimestral, que já conta com 94 edições e mais de 1500 artigos publicados. A revista tem um caráter interdisciplinar, de ampla circulação nacional e é reconhecida por sua excelência, contando com classificações entre A1 e B2 nas avaliações das diferentes áreas de Ciências Humanas, na avaliação da Capes (Coordenação de Aperfeiçoamento de Pessoal de Nível Superior). ${ }^{16}$ Além disso, os pesquisadores do Cebrap publicam sistematicamente "[...] em revistas de referência em humanidades, no Brasil e no

\footnotetext{
${ }^{15}$ Os casos de maior destaque são o livro São Paulo: crescimento e pobreza, de 1976 e as obras, já citadas, de Fernando Henrique, José Serra e Maria da Conceição Tavares, bem como a obra de Francisco de Oliveira e Paul Singer. Disponível em: http://www.cebrap.org.br/v2/contents/view/18.

${ }^{16}$ Disponível em: http://qualis.capes.gov.br/webqualis/publico/pesquisaPublicaClassificacao.seam.
} 
exterior, como também participam do debate público mais amplo por meio de artigos na imprensa."17

Desde o princípio, de acordo Moura e Montero (2009) houve um entendimento do Cebrap de que as publicações eram a mais importante forma de influenciar o pensamento social e político brasileiro, haja vista as limitações à época, provocadas pelas restrições da ditadura. Após esse período, esse entendimento persiste com o fortalecimento das publicações próprias e a busca da continuidade da colaboração de seus pesquisadores com outras mídias. Paul Singer ainda reitera a relevância contemporânea das publicações do Cebrap para a divulgação de sua produção intelectual, a partir do reconhecimento da relevância da revistas Novos Estudos Cebrap: "Quer dizer, a minha ligação mais forte hoje é com a revista, que eu continuo lendo. E se a revista reflete, a vida científica da instituição, não há dúvida de que ela acompanha e contribui para o debate e para a própria transformação da realidade brasileira." (MOURA; MONTERO, 2009, p. 92). De forma geral, pode-se afirmar, portanto, que o caminho das publicações sempre foi a opção institucional mais forte pela qual o Cebrap buscou disseminar suas ideias do ponto de vista de aproximar-se da intervenção junto à conjuntura a partir das posições produzidas no Centro.

\section{Realização de seminários, conferências e debates - estratégia pública}

Além dos "mesões" que, desde os primórdios do Cebrap já se configuravam como workshops capazes de disseminar as ideias ali geradas, o Cebrap tem uma ampla programação de seminário sobre as diversas linhas de pesquisa que desenvolve e temas de relevância política e social, ao longo de sua história. Segundo o próprio Centro, desde sua fundação, em 1969, o Cebrap realiza seminários de discussão das conjunturas política e econômica, do cenário internacional e de temas emergentes da pesquisa em humanidades, intelectuais consagrados, como José Arthur Giannotti, Elza Berquó, Ruth Cardoso, Roberto Schwarz, Rodrigo Naves, Ismael Xavier, Francisco de Oliveira, Paul Singer e Fernando Henrique Cardoso, e grandes nomes das ciências sociais internacionais, como Jurgen Habermas, Michel Foucault, Adam Przeworski, Manuel Castells e Albert Hirshman, tomadores de decisões públicas e figuras de expressão nacional em diversas áreas já debateram seus trabalhos no Cebrap.

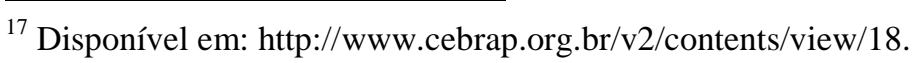


De 2005-2007, por exemplo, foram realizados quase 40 seminários, organizados pelo Cebrap para a discussão de uma grande diversidade de temas de interesse social e político. No ano de 2011, estão registrados 11 seminários e, em 2012, totalizam 9 seminários, reiterando a postura ativa e disseminadora de ideias do Cebrap contemporâneo. ${ }^{18}$ Não há números disponíveis sobre o contingente de pessoas que acessam esses eventos, mas fica clara a intenção de compartilhamento de ideias e oxigenação reflexiva junto a um público formador de opinião.

\section{Capacidade de conferir títulos de graduação acadêmica - estratégia pública}

De 1986 a 2007, o Cebrap manteve um programa de formação interdisciplinar na área de humanidades que reunia estudantes de universidades de todo o país. Até 2003, sob a modalidade Programa de Formação de Quadros Profissionais, o objetivo era aprimorar a formação de quadros jovens - mestrandos e doutorandos - mediante programas sistemáticos de estudo e mediante o convívio contínuo com pesquisadores. A partir de 2003, sob a modalidade de Programa de pós-doutorado, seu objetivo foi mantido, exceto pelo fato de que o grupo reunido passou a ser composto exclusivamente por recém-doutores, que durante dois anos recebem bolsa da Capes. Anualmente, são selecionados quatro pesquisadores para um período de dois anos, fazendo com que o programa conte sempre com oito doutores. Este programa contou com apoio do CNPq, desde 1986, e da Capes, a partir de 1989. ${ }^{19}$

\section{Preparação de estudos e briefs de políticas para policymakers - estratégia privada}

Segundo o Centro, a atuação da organização vai além das pesquisas fomentadas com recursos de agências de fomento e agências internacionais abrangendo também consultorias a órgãos de prefeituras e outras instituições públicas até projetos comparativos internacionais. A organização caracteriza esses trabalhos como passíveis de classificação em cinco categorias:

a) Consultorias e desenvolvimento de subsídios informativos e tecnológicos para orientar prioridades de políticas públicas. Exemplos: Paedi (Pesquisa sobre Atitudes Empresariais para Desenvolvimento e Inovação) [...].

b) Projetos de grande envergadura no levantamento de informações e elaboração de diagnósticos nas áreas de demografia e estudos urbanos.

\footnotetext{
${ }^{18}$ Cf. seu website: http://www.cebrap.org.br/v2/contents/view/31.

${ }^{19}$ Cf. seu website: http://www.cebrap.org.br/v2/contents/view/18.
} 
Exemplos: políticas de habitação e condições habitacionais em São Paulo (SP); o estudo nacional sobre comportamento sexual da população brasileira e percepções do HIV/Aids; a Pesquisa Nacional de Demografia e Saúde da Criança e da Mulher (PNDS) 2006; o projeto Desenvolvimento regional e desigualdades sócio-produtivas: tendências recentes e desdobramentos em termos de políticas públicas.

c) Aqueles realizados em parceria com instituições internacionais e que possuem caráter comparativo entre países. Exemplos: Associativismo e representação popular - comparações entre América Latina e Índia; e Governança e ação coletiva: fundamentos da responsividade. Comparações entre São Paulo, Cidade do México e Nova Delhi.

d) Projetos de ponta em diversas áreas de conhecimento, inclusive humanidades. Exemplos: Terra incógnita: the workings and prospects of the Brazilian Congress; Participation, justice and environmental governance in Brazil: a study of environmental deliberative inclusionary process.

e) Por fim, projetos especiais de pesquisa, desenvolvidos por demandas específicas e financiamentos ad hoc. Exemplos: Mobit (Metodologia para Conceber e Executar Plano de Mobilização Brasileira pela Inovação Tecnológica), realizado em sete países; e Política industrial, inovação e o direito no desenvolvimento econômico. ${ }^{20}$

Ou seja, segundo o próprio Centro, atualmente atendem a instituições diversas, desde "instituições de fomento à pesquisa no Brasil, institutos nacionais de pesquisa, governos municipais, estaduais e órgãos federais, institutos de pesquisa internacionais, agências internacionais de cooperação e de fomento à pesquisa e órgãos internacionais". A lista de instituições para as quais o Cebrap tem prestado serviços ou recebido financiamento mostra sua capilaridade junto aos formuladores de políticas e agências internacionais emanadoras de conhecimento e ideias afetas às políticas públicas. ${ }^{21}$

\section{Exposição na mídia - estratégia pública}

A exposição midiática do Cebrap é constante e significativa, como demonstrada pela seção "Cebrap na Mídia" do website da organização. Artigos para jornais, revistas e emissoras de TV nacionais de ampla circulação e veiculação como Folha de São Paulo, Estadão, Valor, Globo, CBN, TV Cultura, por exemplo; e jornais, revistas e emissoras de TV internacionais como Le Monde Diplomatique, BBC, New York Times, etc. são lugar comum no clipping de notícias da organização em que figuram (e

\footnotetext{
${ }^{20}$ Cf. website do Cebrap, disponível em: http://www.cebrap.org.br/v2/files/upload/diversos/folder_ceb rap_portuguese.pdf.

${ }^{21}$ Algumas citadas são CNPq, Fapesp, Finep, Fundação Carlos Chagas, Fundação Getúlio Vargas, Fundação Seade, Ibama, Ipea, Ministério da Saúde, Prefeitura do Município de São Paulo, Prefeitura do Município de Guarulhos e Prefeitura da Estância Turística de Embu; British Council, Fundação Ford, Fundação MacArthur, IDS/DRC - CFS (Universidade de Sussex), IDS/DRC - CPA (Universidade de Sussex), PNUD, The London School of Economics and Political Science (LSE), The United Nations Population Fund (UNFPA), The William and Flora Hewlett Foundation e Unesco (Idem).
} 
geralmente protagonizam) a exposição de ideias e debate sobre assuntos de interesse social e político brasileiro. Um levantamento qualitativo dessas ocorrências no ano de 2013, a partir de dados fornecidos pelo próprio Cebrap, demonstra isso (Quadro 1):

\section{Quadro 1: Pesquisadores Cebrap presentes na grande mídia em 2013}

\begin{tabular}{|l|l|}
\hline \multicolumn{1}{|c|}{ Veículo Midiático } & Pesquisadores que figuraram nas notícias e debates em 2013 \\
\hline Folha de S. Paulo & $\begin{array}{l}\text { Angela Alonso, Fernando Rugitsky, Marcos Nobre, Institucional } \\
\text { Cebrap sobre pesquisa de base parlamentar, Arilson Favareto }\end{array}$ \\
\hline Globo & Marcos Nobre \\
\hline Le Monde Diplomatique & Monika Dowbor \\
\hline Estadão & $\begin{array}{l}\text { Angela Alonso, Fernando Limongi, José Arthur Giannotti, Monika } \\
\text { Dowbor, Arilson Favareto, Alexandre Freitas Barbosa }\end{array}$ \\
\hline Globonews & Marcos Nobre \\
\hline G1 & Marcos Nobre \\
\hline Valor & Fernando Limongi, Marcos Nobre, Cristian Klein \\
\hline Ciência Hoje & Elza Berquó \\
\hline New York Times & Fernando Limongi \\
\hline Rede Brasil Atual & Andréa de Freitas \\
\hline Blog Terra Magazine & José Rodrigo Rodrigues \\
\hline CBN & José Arthur Giannotti \\
\hline TV Cultura & Maurício Fiore \\
\hline BBC & Alexandre Barbosa \\
\hline Revista Interesse Nacional & Alexandre Freitas Barbosa \\
\hline
\end{tabular}

Fonte: Cebrap na Mídia. ${ }^{22}$

\section{Audiências públicas - estratégia privada}

Um levantamento superficial realizado por simples busca de ocorrências de depoimentos de integrantes do Cebrap nas audiências públicas da Câmara Legislativa, por exemplo, apresentou um resultado tímido de 05 ocorrências relacionadas a

\footnotetext{
${ }^{22}$ Disponível em: http://www.cebrap.org.br/v2/news/category/4.
} 
provimentos de subsídios de conteúdo para debate, entre os anos de 2003 e $2014^{23}$ e 12 citações de estudos da revista Novos Estudos Cebrap. Ainda que o Centro compareça mais significativamente como bibliografia para estudos e pareceres parlamentares e como citações para referência em alguns discursos de parlamentares. ${ }^{24}$

Em outras esferas governamentais, como no caso de audiências municipais da cidade de São Paulo, há casos em que se pode identificar uma participação ativa do Centro como condutor técnico dos debates e do embasamento conceitual e de ideias sobre o tema em discussão. As audiências relativas ao Plano Diretor da cidade e São Paulo, no âmbito do Legislativo demonstram isso. ${ }^{25}$ Dessa forma, ainda que não tenha sido realizada uma varredura dos registros, nas três esferas, sobre essa participação, identifica-se a existência da participação do Cebrap, mesmo que não recorrente e como protagonista das proposições em discussão.

\section{Mailing para divulgação de atividades e conteúdos produzidos na organização - estratégia pública}

O Cebrap conta com serviço de mailing pelo qual divulga os Seminários e eventos que realiza, notícias em que figura o Cebrap e demais conteúdos de interesse do seu público-alvo. ${ }^{26}$

\section{Conclusões}

A partir de todo esse apanhado histórico e analítico sobre a atuação do Cebrap, desde sua fundação até a atualidade, é razoável reiterar o seu enquadramento enquanto um think tank brasileiro. Mais que isso, a exploração da trajetória do Centro, pelos relatos históricos, pelos depoimentos de seus membros e ex-membros não deixa dúvidas

\footnotetext{
${ }^{23}$ O levantamento foi realizado no website da Câmera Legislativa Federal, no mês de junho de 2014. A busca foi realizada por palavra-chave no âmbito de pesquisa geral do site da Câmara (http://www2.camara.leg.br/busca/?q=cebrap\&x=0\&y=0) e identificadas as ocorrências relacionadas ao uso de bibliografia dos pesquisadores do Cebrap manifesta nas falas dos deputados ou como referência para condução de algum debate. Simples citações relacionadas a outros assuntos não foram contabilizadas.

${ }^{24}$ Como exemplo ver: www.camara.leg.br/internet/SitaqWeb/TextoHTML.asp?etapa=5\&nuSessao=035. 4.53.O\&nuQuarto $=11 \&$ nuOrador $=1 \&$ nuInsercao $=0 \& d$ tHorarioQuarto $=09: 20 \&$ sgFaseSessao $=\mathrm{BC} \&$ Data $=$ 11/03/2010\&txApelido=CHICO\%20ALENCAR,\%20PSOL-RJ.

${ }^{25}$ Ver: http://cidadeaberta.org.br/audiencia-sintese-encerra-primeira-etapa-de-discussao-do-plano-diretorna-camara/.

${ }^{26}$ Cf. http://www.cebrap.org.br/v2/news/feed.rss.
} 
que seu protagonismo quase insulado em influenciar o pensamento social e político brasileiro já passou. Essa constatação, no entanto, de maneira alguma o descredencia como um think tank de destaque na atualidade. Como já colocado anteriormente, dentre os aspectos que mais impactaram na capacidade do Centro de se manter na cena principal do pensamento brasileiro destacam-se: a saída de vários de seus intelectuais de destaque para integrarem-se à vida política, reintegrarem-se ao contexto universitário ou compor outros centros de estudos; o desafio do financiamento como fantasma presente no cotidiano de qualquer organização de pesquisa; a dificuldade em constituir uma escola de pensamento que propiciasse a formação continuada de um pensamento cebrapiano; e, o crescimento e profissionalização de outros centros de pesquisa e universidades que tornam significativamente mais competitivo o processo de se constituir em referência intelectual em um panorama social e político de tamanha amplitude como o brasileiro.

De fato, o Cebrap de hoje se mantém como um centro de pesquisa notório, seja pela qualidade reconhecida de sua mais relevante publicação permanente Novos Estudos Cebrap, seja por suas publicações resultantes das diversas linhas de pesquisa desenvolvidas (ver http://www.cebrap.org.br/v2/Researches), seja por seus seminários que contam com a participação de grandes intelectuais nacionais e internacionais, ou seja ainda pela envergadura que vem adquirindo com um novo desenho que conta com a colaboração de uma grande diversidade pesquisadores multidisciplinares, em alguma medida, realizando um retorno às suas origens. Como demonstrado pelo breve levantamento qualitativo de alguns de seus indicadores de visibilidade nos termos de Abelson (2009), a organização se mantém relevante especialmente a partir do uso de “estratégias públicas de disseminação de ideias”, mas também conduzindo ações deliberadas junto a policymakers e a burocracia brasileira, exemplificadas especialmente pelo volume e intensidade de pesquisas por contrato realizadas para órgãos nacionais, das diferentes esferas governamentais e ainda órgãos multilaterais e agências internacionais de desenvolvimento. As estratégias privadas de depoimento junto a legisladores nas diferentes esferas governamentais, porém, existem, mas não se mostram tão expressivas no conjunto de ações do Centro, mostrando uma atuação deliberada mais concentrada nas estratégias públicas.

Não deixa de nos parecer relevante, ainda assim, que o Cebrap, no intuito de se posicionar como um think tank de destaque, reforce suas estratégias enquanto tal. Os desafios de financiamento são atestadamente menores à medida que for maior a 
capilaridade e capacidade de penetração das ideias de um think tank junto aos policymakers e à mídia, tanto especializada quanto geral. Mas conquistar esses espaços nos tempos atuais requer investimentos de recursos financeiros, intelectuais e institucionais. Pouca valia terão os resultados das pesquisas realizadas pelos think tanks se eles não alcançarem seu público de interesse: do ponto de vista do aproveitamento de “janelas de políticas" (KINGDON, 1984 apud CAPELLA, 2006), a grande mídia, a mídia especializada e, por conseguinte, a opinião pública; do ponto de vista decisório, os burocratas governamentais e os policymakers.

As "cartilhas" dos think tanks estadunidenses e anglo-saxões em geral, mais popularmente conhecidos por serem mais profissionalizados e competitivos, entendem que o processo de empreendedorismo político e marketing de ideias é tão relevante quanto a condução da pesquisa em si. Ou ainda, como nos think tanks do século XXI, a compilação de pesquisas realizadas por outras organizações é um caminho frutífero a ser associado com a pesquisa in house (HART; VROMEN, 2011; STONE, 2007). Para que ela se transforme em ação pública é imprescindível que chegue a seus destinatários. O protagonismo do Cebrap em seus 'tempos de ouro' se beneficiou não somente da capacidade intelectual, mas também de manobra institucional de seus principais pesquisadores para que o Centro sobrevivesse e se destacasse. Houve uma conjunção de oportunidades fortuitas, mas houve também articulação e capacidade de aproveitamento dessas oportunidades. Nos tempos de hoje, as regras e requisitos para se destacar e superar, inclusive, o desafio do financiamento são outras. E qualquer think tank precisa se planejar e se articular para suplantá-los. Um maior equilíbrio entre as estratégias públicas e as estratégias privadas de marketing de ideias pode ser um caminho produtivo para um posicionamento mais incisivo do Cebrap no horizonte da influência no processo político e, por conseguinte, o levantamento de recursos de sobrevivência mais facilitados. 


\title{
Brazilian think tanks and its contributions to social and political thought in Brazil: a historical-exploratory review about Brazilian Center for Analysis and Planning (Cebrap)
}

\begin{abstract}
To delineate the trajectory of the Brazilian political and social thought one can't avoid a look at think tanks (TTs). Although its definition is nascent and controversial, one can identify cases in which no doubt lies. Emblematic case in the Brazilian context is CEBRAP - Brazilian Center for Analysis and Planning. Understood as a typical TT - organization dedicated to the research and dissemination of ideas regarding public policy - CEBRAP harbored great intellectuals of the country, serving as space of debate on major national issues. Thus it became a reference in the social sciences, policy, philosophy, and literary and artistic criticism. Fernando Henrique Cardoso, José Giannotti, Paul Singer, Elza Berquó, Juarez Brandão, Francisco de Oliveira, José Serra, Candido Procópio, Ruth Cardoso, Vilmar Faria, Bolivar Lamounier; are among its leading intellectuals. CEBRAP also inspired the creation of similar institutes in matters that its prominence justifies its centrality in the Brazilian intellectual scene for decades. To explore this, the article makes a theoretical elucidation of TTs and CEBRAP as such; followed by a historical-political review of the center and the impact of its intellectual productions; and finally, an analysis of its position as a think tank face to the theories of TTs.
\end{abstract}

Keywords: Think tanks; Cebrap; Brazilian Social and Political Thought.

\section{REFERÊNCIAS}

ABELSON, D. E. Do think tanks matter? Assessing the impact of public policy institutes. Montreal: McGill-Queen's University Press, 2009.

CAPELLA, A. C. N. Perspectivas teóricas sobre o processo de formulação de políticas públicas. BIB, São Paulo, n. 61, p. 25-52, 1º sem. 2006.

CHACEL, J. Think tanks in Brazil: the Case of Instituto Brasileiro de Economia as an Illustration. In: MCGANN, James G, WEAVER, R. Kent. (ed.). Think tanks \& Civil Societies: Catalysts for Ideas and Action. New Brunswick: Transaction Publishers, 2005.

COSTA, Gilberto. Série Ipea/História - A liberdade do pensamento. Ano 8, Edição 64, 2011. Disponível em: <www.ipea.gov.br> Acesso em: 10 out. 2013. 
CPDOC/FGV. A Era Vargas: dos anos 20 a 1945. Diretrizes do Estado Novo - Política e Administração. In: CPDOC/FGV. A Era Vargas - $1^{\circ}$ tempo - dos anos 20 a 1945. Brasília: Fundação Getúlio Vargas, 1997. Disponível em: <http://cpdoc.fgv.br/producao/dossies/AEraVargas1/anos37-45/PoliticaAdministracao> Acesso em: 17 Out. 2013.

CRAWFORD, Alan. Think tanks: A New Brand of Lobbying Firms? Public Affairs Council, Washington, Abr. 2013. Disponível em: <http://pac.org/news/think-tanks-anew-brand-of-lbbying-firms>. Acesso em: 15 jun. 2013.

GERVAISEAU, Henri Arraes. Retrato de Grupo: 40 Anos do Cebrap. São Paulo: CosacNaify, 2009. 1 vídeo-disco (100 min.). In: MOURA, Flávio; MONTERO, Paula. Retrato de Grupo: 40 Anos do Cebrap. São Paulo: CosacNaify, 2009.

HART, P.; VROMEN, A. A new era for think tanks in public policy: international trends, Australian realities. The Australian Journal of Public Administration, v. 67, n. 2, p. 135-148, 2011.

MCGANN, J. Global Go To Think tanks Report. Philadelphia: University of Pennsylvania, 2013. Disponíveis em: <http://gotothinktank.com/dev1/wpcontent/uploads/2013/07/2012_Global_Go_To_Think_Tank_Report_-_FINAL-1.28.

13.pdf> Acesso em: 12 abr. 2013.

MCGANN, J.; JOHNSON, E. Comparative think tanks, politics and public policy. Cheltenham: Edward Elgar, 2005.

MCGANN, J.; WEAVER, R (Org.). Think tanks and civil societies: catalysts for ideas and action. New Brunswick/ Londres: Transactions Publishers, 2002.

MEDVETZ, Thomas. Think tanks as an emergent field. New York: The Social Science Research Council, 2008.

MEDVETZ, Thomas. "Public Policy is like having a vaudeville act": languages of duty and difference among think tank-affiliated policy experts. Qualitative Sociology, n. 33, p. 549-562, jun. 2010.

MONCADA, Andrea. Are think tanks the new lobbyists? On Think tanks: independent research, ideas and advice. 8 mar. 2013. Disponível em: <http://onthinktanks.org/2013/03/08/are-think-tanks-the-new-lobbyists> Acesso em: 13 Abr. 2013.

MOURA, Flávio; MONTERO, Paula. Retrato de Grupo: 40 Anos do Cebrap. São Paulo: CosacNaify, 2009. 328 p.

PAUTZ, H. Revisiting the think tank phenomenon. Public Policy and Administration, n. 26, p. 419-435, jan. 2011.

RICH, A. Think tanks, public policies and politics of expertise. New York/ Cambridge: City college of New York; Cambridge University, 2004. 272 p. 
SILVERSTEIN, Ken. The Great Think-Tank Bubble. New Republic Magazine, 19 fev. 2013. Disponível em: <http://www.newrepublic.com/article/112381/salary-inflationbeltway-think-tanks>. Acesso em: 13 jul. 2013.

SORJ, Bernardo. A construção intelectual do Brasil contemporâneo: da resistência à ditadura ao governo FHC. Rio de janeiro: Jorge Zahar, 2001.

STONE, D. Recycling bins, garbage cans or think tanks? Three myths regarding policy analysis institutes. Public Administration, v. 85, n. 2, p. 259-278, Jun. 2007.

STONE, D.; DENHAM, A. (Org.). Think tank traditions: policy research and the politics of ideas. Manchester/ Nova York: Manchester University Press, 2004.

TEIXEIRA, T. S. Brazilian think tanks and their search for identity and recognition. Disponível em: <http://lasa.international.pitt.edu/members/congresspapers/lasa2012/files/32001.pdf> Acesso em: 03 mar. 2013. 